\title{
TRADUÇÃO \\ Redistribuição e reconhecimento do ponto de vista da igualdade real: Anderson e Honneth através das lentes de Babeuf ${ }^{1}$
}

Jean-Phillipe Deranty²

Resumo: Neste artigo, meu objetivo é enfrentar os problemas relacionados à redistribuição por meio de uma apropriação crítica do paradigma distributivo. Vou partir dos escritos de dois dos mais importantes críticos do paradigma distributivo na filosofia política contemporânea, Elizabeth Anderson e Axel Honneth, cujos argumentos se sobrepõem de várias maneiras. A concepção de igualdade democrática ou relacional de Anderson partilha uma série de elementos conceituais chave com a teoria do reconhecimento e da liberdade social de Honneth. Os dois autores oferecem pontos de referência eminentes e convergentes para elucidar criticamente problemas de redistribuição em relação a problemas de reconhecimento. Nas seções 1 e 2, apresento os autores a partir de um triplo ponto de vista: como suas respectivas teorias do reconhecimento se sobrepõem e se afastam uma da outra; quais são as implicações disso para os problemas de redistribuição; qual é a contribuição de suas concepções de "igualdade real". Na seção 3, abordo os dois autores criticamente, do ponto de vista da "igualdade real", tomando por base as tradições a que eles se referem para elaborar suas respectivas afirmações. Questionando, por fim, a leitura que Anderson faz de Babeuf, o utilizo para levantar diversas questões críticas às versões do igualitarismo apresentadas por ela e por Honneth.

Palavras-chave: Honneth; Anderson; Babeuf; Redistribuição; Reconhecimento; Igualdade real.

Há dois modos de entender "redistribuição" no contexto das discussões sobre justiça. Primeiro, simplesmente como um dos problemas a serem enfrentados no que diz respeito à justiça: o que é uma distribuição equitativa dos benefícios e dos fardos envolvidos na vida conjunta em sociedade, enquanto parte de uma teoria da justiça mais ampla? "Redistribuição” também designa uma forma específica de definir justiça em geral, baseada na ideia de que o problema central da justiça

1 Tradução de "Redistribution and recognition from the point of view of real equality: Anderson and Honneth through the Lens of Babeuf", publicado em uma versão diferente em D. Celentano and L. Caranti, Paradigms of Justice: Redistribution, Recognition, and Beyond. London: Routledge, 2020 (DOI: https://doi.org/10.4324/9781003099932). Tradução de Felipe Ribeiro (USP), Izabela Loner Santana (UFABC), Nathalie de Almeida Bressiani (UFABC) e Pedro Casalotti Farhat (UFABC).

2 Macquarie University, Sydney, Australia. 
é o problema da distribuição equitativa. Essa abordagem, que pode ser chamada de paradigma da "justiça distributiva", tem sido central na filosofia política angloamericana nas últimas quatro décadas, na esteira do trabalho seminal de John Rawls. No que se segue, buscarei enfrentar os problemas relacionados à redistribuição por meio de uma apropriação crítica do paradigma distributivo. Vou partir dos escritos de dois dos mais importantes críticos do paradigma distributivo na filosofia política contemporânea, Elizabeth Anderson e Axel Honneth, cujos argumentos se sobrepõem de várias maneiras. A concepção de igualdade democrática ou relacional de Anderson partilha uma série de elementos conceituais chave com a teoria do reconhecimento e da liberdade social de Honneth. Os dois autores oferecem pontos de referência eminentes e convergentes para elucidar criticamente problemas de redistribuição em relação a problemas de reconhecimento.

0 ângulo escolhido para estudar criticamente esses problemas, todavia, será mais específico. Apesar das sobreposições, os dois pensadores se afastam um do outro, sobretudo porque suas inspirações repousam em duas tradições políticas distintas. Anderson busca recuperar a tradição republicana, Honneth a socialista. Uma das principais características que define as duas tradições, e também que as distancia da corrente dominante do liberalismo, é a rejeição de teorias formais da igualdade e a tentativa de desenvolver teorias da "igualdade real". Nas seções 1 e 2 , apresento os autores a partir de um triplo ponto de vista: como suas respectivas teorias do reconhecimento se sobrepõem e se afastam uma da outra; quais são as implicações disso para os problemas de redistribuição; qual é a contribuição de suas concepções de "igualdade real".

$\mathrm{Na}$ seção 3, abordo os dois autores criticamente, do ponto de vista da "igualdade real", tomando por base as tradições a que eles se referem para elaborar suas respectivas afirmações. Na sequência das revoluções americana e francesa, na primeira metade do século XIX, o movimento republicano rejuvenescido e o movimento socialista que emergia eram muitas vezes indiscerníveis no que diz respeito a seus objetivos e estratégias políticas. Independentemente de ter sido usado como inspiração ou como alternativa indesejada, um ponto de referência importante foi o movimento associado ao nome de Babeuf e ao "Manifesto dos Iguais", que defendia uma proposta radical de redistribuição de riqueza para alcançar a igualdade plena. Em sua retomada do "republicanismo radical", Elizabeth Anderson explicitamente contrapõe sua abordagem e a vertente que a inspira a esse modo de enquadrar a "igualdade real". Eu questiono a leitura que ela faz de Babeuf e o utilizo para levantar diversas questões críticas às versões do igualitarismo apresentadas por ela e por Honneth. 


\section{O conceito republicano de "igualdade real" de Elizabeth Anderson}

\section{a. A crítica de Anderson à "justiça distributiva" e o conceito "real" de igualdade}

O paradigma da "justiça distributiva" inclui os autores mais influentes da corrente dominante da filosofia política anglo-americana, como Ronald Dworkin, Richard Arneson, G. A. Cohen ou John Roemer, que definiram os problemas de justiça em termos de distribuição equitativa. O principal pressuposto dessas abordagens é o de que as vicissitudes da vida social, sobretudo a complexidade da vida econômica moderna e a arbitrariedade que caracteriza a distribuição dos atributos naturais entre os indivíduos, se combinam para violar o princípio básico da justiça de que todo indivíduo deveria receber o que lhe é devido. Alguns recebem menos do que deveriam em função de circunstâncias pelas quais não são responsáveis, enquanto outros recebem mais do que outros também por uma razão não justificável. Dessa perspectiva, o problema da justiça se torna principalmente um problema de distribuição equitativa. Nessa abordagem, os bens paradigmáticos são os bens econômicos, mas outros "bens" também são considerados, tais como posições de prestígio e poder, oportunidade ou bem-estar. De fato, os debates no interior desse paradigma buscam decidir precisamente quais daqueles "bens" são a "moeda" correta da "justiça igualitária" (Cohen, 1989). Mesmo no caso de bens que não são diretamente econômicos, no entanto, a mensuração primária da desigualdade distributiva se dá em termos de recursos materiais, em termos de propriedade e renda, e a compensação equitativa é discutida em termos de redistribuição financeira através de ações estatais, sobretudo seguro e taxação. Nessa abordagem, a igualdade é um critério normativo central, assim como a igualdade de tratamento, mas a igualdade é concebida em um sentido exclusivamente distributivo e a redistribuição equitativa em termos materiais.

O trabalho seminal de Elizabeth Anderson sobre a igualdade se desenvolveu, em grande medida, como uma resposta crítica a essa influente abordagem da justiça. Para ela, o conceito "real" de igualdade é relacional e se refere "não tanto à distribuição de bens quanto às relações entre pessoas" (1999, p. 312). A igualdade não é, primeiro e antes de tudo, igualdade de atributos, ou de oportunidades, ou de bem-estar, mas uma qualidade das relações sociais; aquela em que cada pessoa é capaz de "se colocar como um igual perante os outros" (idem, p. 313). O oposto da justiça não é primariamente a vantagem sem mérito ou a desvantagem imerecida, mas relações desiguais, em outras palavras: a opressão de alguns sobre outros, que se manifesta em relações de violência, dominação, discriminação ou exclusão. O ideal de justiça, portanto, não é um no qual todos os indivíduos desfrutam precisamente do que merecem e nada mais, mas uma sociedade de iguais. A igualdade "real", 
portanto, também pode ser definida como "democrática", já que aponta para um ideal social em que todo indivíduo tem um valor social igual. Igualdade plena significa "viver em uma comunidade democrática, em oposição a uma hierárquica".

O critério central e o medium da justiça nesse modelo é a qualidade das interações entre pessoas. Anderson compreende isso como uma mudança de uma perspectiva "em terceira pessoa" sobre a justiça, que calcula a equidade das estruturas sociais de um ponto de vista externo, para uma perspectiva "em segunda pessoa", que olha para a estrutura de interações interpessoais: "o que é devido a uma pessoa diz respeito a quais demandas as pessoas têm o direito de fazer sobre a conduta das outras, com respeito a como eles tratam os demandantes e seus interesses" (2010b, p. 19). Como resultado, a justiça dos arranjos sociais pode ser especificada, em termos comunicativos, como a capacidade universal de exigir e oferecer razões: "a igualdade democrática considera duas pessoas iguais quando cada uma aceita a obrigação de justificar suas ações por princípios aceitáveis pela outra, e quando elas tomam a consulta mútua, a reciprocidade e o reconhecimento como dados".

O modelo de justiça que está no pano de fundo é um ideal republicano de igual participação na vida social. Podemos dizer que o modelo republicano especifica o próprio conceito de igualdade. Anderson, por sua vez, transfere esses dois elementos (o modelo republicano de democracia e o conceito de igualdade que o beneficia) para uma metodologia apropriada a eles, a saber, uma teoria do contrato social, que ela herdou de seu professor John Rawls. Nesse sentido, a definição conceitual de igualdade corresponde a uma descrição de um modelo político republicano, podendo ser interpretada como uma aplicação da teoria do contrato social: a justiça como igualdade significa que "o indivíduo tem o direito de participar, que outros reconhecem a obrigação de ouvir respeitosamente e de responder aos seus argumentos, que ninguém precisa se curvar e se ajustar aos outros ou se colocar como inferior a eles como condição para ter suas demandas ouvidas" (1999, p. 313). 0 conceito, o método e o ideal social se reforçam mutuamente. Isso é apreendido na seguinte afirmação: "aquilo que os cidadãos devem uns aos outros são as condições sociais necessárias às liberdades das quais as pessoas precisam para funcionarem como cidadãos iguais" (idem, p. 320).

Esse modelo de igualdade relacional ou democrática abre muito espaço para a desigualdade econômica. Para Anderson, os mais "talentosos" e mais diligentes deveriam ser recompensados por seus esforços, dentro das restrições do princípio da diferença. Ela se opõe aos igualitaristas da fortuna não apenas porque eles desrespeitam ricos e pobres, talentosos e não talentosos, ao fazerem com que o estado examine as escolhas de vida para determinar se os indivíduos foram responsáveis para seu destino social, mas também porque é importante assegurar 
a possibilidade da desigualdade justificada, pois faz parte da justiça que os que merecem recebam aquilo que merecem. Queremos evitar recompensas imerecidas, mas também precisamos promover o talento. Isso é mais equitativo para aqueles que estão em melhores condições, mas também para os que estão em condições piores, já que eles se beneficiam da maior produtividade alcançada pelos primeiros (idem, p. 326; 2010b, p. 20-1). Nesse modelo, a distribuição importa, mas não é, ela mesma, uma parte intrínseca da igualdade "real" (relacional, democrática). Se os menos privilegiados recebem os recursos básicos e as oportunidades que lhes permite "se colocar como iguais frente aos outros", e se os mais "talentosos" recebem uma recompensa equitativa e são de fato incentivados a serem mais produtivos para benefício de todos os demais, então a distribuição deixa de ser um problema de justiça. É verdade que a igualdade distributiva é cega a vários outros aspectos da injustiça, sobretudo a todos aqueles aspectos que impedem que os indivíduos funcionem como cidadãos iguais nas diferentes esferas da vida social.

\section{b. Realizando a igualdade}

O trabalho de Elizabeth Anderson também pode ser lido como uma tentativa de repensar a justiça do ponto de vista da "igualdade real" num segundo sentido, nos termos da realização efetiva de demandas por justiça. Essa é uma das dimensões de sua defesa de uma abordagem em segunda pessoa da justiça. Essa perspectiva considera quais demandas justificadas um indivíduo ou um grupo pode fazer a outros indivíduos, com relação a um bem específico, em nome da igualdade. Uma das dimensões dessa justificabilidade diz respeito precisamente à possibilidade de que a demanda seja ou não satisfeita, em outras palavras, se é realmente possível satisfazer a demanda por igualdade, pela realização da justiça. Isso não é apenas uma questão empírica, mas também conceitual. Diz respeito à noção mesma de justificabilidade, àquilo que faz com que uma demanda seja uma demanda justificada. Como ela escreve: "é irrazoável exigir que os agentes satisfaçam um princípio que eles são incapazes de seguir. As exigências da justiça devem ser talhadas para as capacidades cognitivas e comportamentais dos agentes em geral” (2010b, p. 19).

Anderson está preocupada com a realização efetiva da igualdade em um segundo sentido, que está relacionado às suas várias tentativas de especificar, por meio de discussões elaboradas e muito bem informadas, como o princípio fundamental da igualdade relacional deve ser aplicado a problemas políticos específicos. Ela buscou superar, de modo consistente, o hiato entre a filosofia política pura e normativa, os programas políticos e a política real. Por exemplo: seu artigo seminal de 1999 sobre "o sentido da igualdade" conduz a discussões precisas sobre as implicações políticas de seu conceito relacional de autonomia para a compensação devida a pessoas 
com deficiência ou para o apoio a pessoas que escolhem ter filhos. Em diversos artigos (2016a; 2016b), ela defendeu políticas de seguro social, resgatando tanto as origens históricas quanto a força conceitual e normativa dessas propostas. Ela também estudou as implicações da igualdade relacional para o problema dos "riscos de mercado" na sociedade contemporânea, isto é, quais tipos de restrições deveriam ser impostos aos mercados para mitigar resultados injustos (2008). Em seu trabalho recente sobre a democracia no ambiente de trabalho, ela mostrou as implicações de sua teoria crítica da firma enquanto um espaço de governança para o gerenciamento e a política econômica (2015a).

Anderson, por fim, está preocupada com um terceiro ponto, relacionado à metodologia filosófica, para que a igualdade se torne "real". Ela contrasta sua abordagem com aquelas de filósofos morais e políticos que desenvolvem propostas ideais independentemente dos fatos históricos e sociológicos das sociedades humanas (2015b). Anderson procurou ancorar suas afirmações normativas em descrições densas das sociedades humanas, valendo-se de teoria econômica, para discutir aspectos técnicos da justiça distributiva; da história dos movimentos sociais, para mostrar como seu modelo conceitual formaliza as demandas reais de indivíduos e grupos que buscam justiça; da história e da sociologia, para propor uma teoria republicana original da firma (2017).

Essas referências às ciências sociais e históricas não são usadas apenas para superar o hiato entre a análise normativa e a aplicação de princípios, mas para a própria análise de princípios normativos. Anderson descreve essa abordagem da filosofia política como uma forma de pragmatismo (2014a). 0 método pragmático está de acordo, de modo crucial, com a definição de "igualdade real" e com a teoria política republicana. Além disso, na concepção pragmática, a igualdade só possui uma chance real de ser efetivada se for concebida como resultado de interações interpessoais livres, baseadas principalmente na troca de justificativas. Nas Amherst Lectures de 2014, Anderson fecha o círculo de modo performático, argumentando que é precisamente por meio do estudo de como os movimentos sociais reais garantiram mais igualdade que podemos aprender como a igualdade pode se tornar real (2014a). Este é um gesto performático poderoso, pois está ancorado em uma compreensão histórica e realista a respeito da realização efetiva da igualdade por meio de atividades de contestação (e não apenas da argumentação moral), com base nas quais pode-se discutir precisamente o que a igualdade relacional requer.

\section{c. "Igualdade real" como uma demanda histórica.}

Por fim, outro sentido de "igualdade real" diz respeito à história das ideias políticas e aos argumentos levantados na sequência das revoluções modernas, 
e contrapõe a igualdade formal à igualdade "real", ou "efetiva", ou "plena", ou "material". Anderson vincula explicitamente seu modelo de justiça e igualdade à tradição histórica do republicanismo. No interior dessa tradição, a posição “radical”, à qual Anderson se filia (2015a, p. 51), se caracteriza precisamente pela tentativa de "tornar a igualdade real", contra as tentativas conservadoras de limitá-la, e contra as compreensões meramente formais dela, notadamente liberais (sobre as raízes históricas da “igualdade real”, ver Rosanvallon, 2013, p. 12-74). Ela também contrapõe a compreensão republicana radical da "igualdade real" com as alternativas socialistas, apesar de suas raízes comuns (Hayat, 2018), sobretudo porque os socialistas interpretam as concepções "não apenas formais" de igualdade como concepções que asseguram a violação da propriedade privada, e tendem a levantar demandas mais fortes do que os republicanos a respeito das disposições éticas necessárias aos indivíduos.

Essa inspiração histórica e republicana, que está por trás do trabalho de Anderson, fica particularmente evidente em seu trabalho sobre democracia no ambiente de trabalho e igualdade racial. No capítulo 5 de 0 imperativo da integração (2010a, p. 89-110), por exemplo, ela reconstrói a longa história da luta por plena igualdade racial nos EUA. O argumento central adotado por ela é o mesmo desenvolvido e defendido pelos abolicionistas negros e republicanos radicais, que buscaram garantir a "igualdade plena" argumentando que esta igualdade estava contida analiticamente na própria ideia de república. Nessa visão, a noção de igualdade "real" ou "plena" denota todos os direitos que os indivíduos têm, enquanto cidadãos, de participarem como iguais em todas as diferentes esferas da vida social e política, inclusive no trabalho, no mercado de trabalho e em processos coletivos de tomada de decisão.

\section{A crítica de Honneth às teorias políticas procedimentais}

\section{a. A liberdade social e a igualdade relacional de Honneth}

Honneth endossaria muitas das características do modelo de "igualdade relacional" de Anderson para seu modelo de reconhecimento. Como ela, ele pensa o reconhecimento da perspectiva da segunda pessoa, como uma demanda fundamental que os indivíduos fazem aos outros, ancorados na afirmação fundamental de serem capazes de "se colocar como um igual perante os outros" (1995, p. 112). De fato, Anderson cita Honneth para articular sua concepção relacional de igualdade (1999, p. 314). Ambos defendem que as demandas por reconhecimento se aplicam às diferentes esferas da sociedade. Em “Qual é o sentido da igualdade?”, Anderson parte da teoria de Sen sobre as capacidades para levar as demandas por igualdade a todas as esferas da vida social. Segundo ela, demandas por igualdade se aplicam a três esferas, as 
quais correspondem às esferas de reconhecimento de Honneth: nas quais as pessoas funcionam enquanto seres humanos, enquanto participantes de um sistema de produção cooperativa e enquanto cidadãos de um estado democrático (1999, p. 317). Da mesma forma, em sua reformulação do reconhecimento em $O$ direito da liberdade, Honneth passa a apresentar o modelo do reconhecimento como um estudo sobre "os fundamentos sociais da vida democrática". Em outras palavras, ele interpreta o ideal de reconhecimento como uma demanda por uma vida democrática plena, que perpassa todas as esferas da vida social, no espírito do modelo compreensivo de "igualdade democrática" desenvolvido por Anderson. Os dois pensadores tomam a expansão histórica dos direitos, dos direitos civis aos políticos e aos sociais, como prova de que as demandas por reconhecimento e igualdade perpassam todas as áreas da vida social. Ambos argumentam que o reconhecimento jurídico não é suficiente, e que garantir a igualdade democrática no sistema produtivo também é essencial para o reconhecimento "real" e para a igualdade "real". Anderson vai mais longe que Honneth nesse ponto, pois vai mais fundo nas estruturas de dominação que operam nas firmas modernas. Mas eles compartilham o argumento geral, a saber: que o reconhecimento, ou a igualdade democrática, coloca restrições à organização econômica e que a justiça requer muito mais nessa esfera do que apenas liberdade para estabelecer contratos (Honneth, 2012a, p. 56-75). Por último, ambos vinculam suas teorias a lutas reais por emancipação. Eles o fazem, em primeiro lugar, como uma evidência substantiva para as definições conceituais de justiça que defendem. Movimentos sociais históricos iluminam o que a justiça real significa para pessoas reais: igualdade plena nas relações sociais. Em segundo lugar, os dois pensadores atribuem grande parte da dimensão de "realização", ou aplicação, ou implementação, de suas teorias a movimentos sociais. Uma característica das teorias "democráticas" da justiça propostas está em aprender com o público como a justiça deveria ter sido realizada no passado e como talvez possa ser realizada no futuro.

Apesar dessas fortes sobreposições, os conceitos de reconhecimento e igualdade relacional formalizam a justiça de maneiras distintas. Essas diferenças podem ser vinculadas às diferenças entre concepções republicanas e socialistas. Na concepção de Anderson sobre as relações sociais de igualdade, o ideal social é inerentemente político: o que mede e assegura a igualdade é o fato de que os indivíduos "vivem juntos em uma comunidade democrática" (1999, p. 313). A fórmula que resume a concepção de igualdade real da autora explicita claramente sua inclinação republicana: "aquilo que os cidadãos devem uns aos outros são as condições sociais das liberdades, as quais são necessárias para que as pessoas funcionem como cidadãos iguais" (idem, p. 320). Anderson tem em mente dois sentidos específicos de "social" quando fala em "condições sociais da liberdade". Primeiro, ela se refere às interações recíprocas entre indivíduos em termos de demandas justificadas que um levanta ao outro. A 
questão aqui é: estão todos de acordo com os termos da relação? Segundo, "social" também significa coletivo, onde o coletivo é conceitualizado como o agregado de todos os encontros fictícios entre parceiros em interação. Como dito acima, esse modelo de interação em segunda pessoa está de acordo com o método da teoria do contrato social que ela toma emprestado de Rawls e da tradição republicana de maneira mais ampla.

Nesse sentido "republicano" do "social", o indivíduo é um agente autônomo cujas demandas frente aos demais derivam de seus direitos inalienáveis como um ser livre. Reconhecimento, nesse sentido, é uma confirmação [acknowledgement] recíproca entre seres autônomos, que é extrínseca aos indivíduos. Eles contam uns com os outros instrumentalmente para a satisfação de suas demandas e dependem, nesse sentido, de relações de reconhecimento, mas os indivíduos são o que são independentemente da relação. Em Honneth, ao contrário, o reconhecimento é intrínseco à própria construção da identidade individual. No primeiro modelo, apresentado em Luta por reconhecimento, essa ideia é apreendida em termos antropológicos e psicológicos: o próprio processo de formação da identidade repousa na afirmação do self por outros. O self é formado por meio da internalização das atitudes dos outros perante ele. As esferas de reconhecimento correspondem aos diferentes domínios da vida social em que os selves estão "sob o olhar" dos outros de maneiras específicas. Neste modelo, a autonomia não depende dos outros de modo instrumental (se eles me concedem ou não aquilo de que preciso para que minha liberdade seja efetivamente realizada), mas intrínseco. Só posso estabelecer uma autorrelação positiva comigo mesmo, o que corresponde à maneira inicial de Honneth de redefinir a norma fundamental da liberdade como autodeterminação e autorrealização, se as atitudes direcionadas a mim o permitirem, ao menos minimamente.

Em $O$ direito da liberdade, a mesma ideia é colocada em termos mais formais, por meio da ideia de “liberdade social”. Concepções negativas de liberdade são versões empobrecidas, que não captam o sentido mais rico da liberdade enquanto autodeterminação e autorrealização, pois se concentram apenas nos obstáculos externos e não no conteúdo e na estrutura da autonomia. Um sentido mais rico de autonomia depende de uma compreensão "densa”, que requer, por sua vez, uma consideração da estrutura "social" dessa liberdade. Afinal, aqueles objetivos mais importantes, que eu quero alcançar para me realizar plenamente, e com isso alcançar a autodeterminação plena, só fazem sentido se os outros com quem me relaciono para a realização desses fins também realizam os seus fins comigo, ao mesmo tempo. A realização dos meus fins requer, de modo intrínseco e não instrumental, que outros também sejam capazes de realizar seus próprios fins. 0 reconhecimento recíproco entre os indivíduos envolvidos é, aqui, uma condição constitutiva da autonomia de 
cada indivíduo: "a experiência recíproca de nos vermos confirmados nos desejos e objetivos do outro, uma vez que a existência do outro representa uma condição para a satisfação de nossos próprios desejos e objetivos" (2014, p. 45). Esta é uma concepção "social" de liberdade porque, para cada tipo particular de fim realizável pelo indivíduo, há um tipo específico de "nós", um tipo específico de coletividade: uma amizade, um casal, uma família, um mercado de trabalho, um mercado de mercadorias, um estado, uma nação, uma cultura. O conceito de "social" vai mais fundo aqui do que em uma concepção republicana. Dizer que cada indivíduo requer condições sociais para sua liberdade significa: cada um deve levar em conta os desejos e objetivos do outro na própria formulação de seus desejos e objetivos, relacionando com isso suas necessidades, crenças e desejos individuais com o tipo relevante de coletividade em questão. Em outras palavras, a solidariedade, o levar em conta o outro e a coletividade, se torna uma condição intrínseca da autonomia de cada self e guia a ordenação da "sociedade bem ordenada" (2017). Por outro lado, são necessárias estruturas sociais que tornem isso possível e reforcem esses mecanismos recíprocos, tanto instituições formais quanto uma cultura pública. Este não é mais um ideal republicano, mas socialista. Um ideal que compreende a sociedade justa como uma ordem de cooperação, ou como uma associação de parceiros que não são apenas iguais em termos de direitos à autorrealização, mas são codependentes nessa busca. Neste modelo, o coletivo vem da lógica da reciprocidade que anima cada indivíduo em sua relação com os outros. Longe de ser externo às unidades singulares, o coletivo dá sustentação às ações individuais na medida em que todas estas são intrinsecamente atreladas ao bem-estar de todo e qualquer indivíduo. Apesar de todas as suas diferenças metodológicas, uma visão similar de socialismo é defendida por G. A. Cohen, com seu "princípio de comunidade" (2009).

\section{b. A crítica de Honneth à "justiça distributiva”}

Dadas essas diferenças entre os modelos de Honneth e Anderson, quais são as implicações para a distribuição, enquanto um problema e enquanto um paradigma? Como Honneth enfrenta essas questões do ponto de vista da "igualdade real"? Dado que ele visa abordar essas questões a partir de uma perspectiva "socialista" e dada a importância da preocupação com a igualdade real nessa tradição $0^{3}$, parece que a

\footnotetext{
3 Isso pode parecer controverso, dada a famosa antipatia de Marx pela igualdade (Wood, 2014). No entanto, como Wood nos lembra, a rejeição de Marx e Engels à igualdade baseava-se precisamente na ideia de que tal objetivo de igualdade havia se tornado obsoleto; fazia sentido na época da revolução burguesa (Francesa), mas deveria ser substituído pelo objetivo de abolição de todas as classes. Como Engels escreveu: "A ideia da sociedade socialista enquanto reino da igualdade é uma ideia francesa unilateral que repousa sobre a velha 'liberdade, igualdade, fraternidade' - uma ideia justificada enquanto estágio de desenvolvimento em seu próprio tempo e lugar, mas que, como todas as ideias unilaterais das escolas socialistas anteriores, deve ser superada" (Engels apud Wood,
} 
questão é justificada, mesmo que, como veremos, Honneth não faz da "igualdade real" um tema central em seu resgate da tradição socialista.

No que diz respeito ao paradigma de justiça distributiva, a questão é complicada, pois Anderson e Honneth ocupam diferentes posições em relação a ele. Anderson analisa o paradigma a partir de dentro da corrente dominante do campo anglo-americano, no qual o paradigma é central, e coloca sua abordagem diretamente contra tal campo. Ela compreende sua abordagem "relacional" na esteira de Rawls. Como vimos, ela descreve a metodologia do contrato social de Rawls como um modo de realizar sua concepção republicana de "igualdade real", pois visa garantir que as demandas que cada pessoa poderia fazer à sociedade, poderiam ser feitas desde o ponto de vista de qualquer outra pessoa. Isso pode ser interpretado, argumenta, como equivalente à ideia de que a justiça diz respeito a "quais demandas as pessoas podem fazer às outras".

Honneth também critica o paradigma da "justiça distributiva" em termos que ecoam diretamente os de Anderson. Assim como ela, ele assinala que a justiça não deve ser discutida primariamente nos termos de uma distribuição equitativa dos bens, mas nos termos da qualidade das relações sociais. A questão central da justiça é, para ele, uma concepção robusta de autonomia e "o que nos ajuda adquirir autonomia não é feito do mesmo material que aquilo que pode ser distribuído; é algo elaborado a partir de relações vivas de reconhecimento recíproco, que são justas na medida em que nos permitem valorizar reciprocamente nossas necessidades, crenças e capacidades" (2012b, p. 41).

Ainda assim, é principalmente Rawls aquele que Honneth tem em vista em sua ampla crítica à corrente dominante da filosofia política. De fato, diversos igualitaristas da fortuna, sobretudo Cohen, escrevem contra Rawls e rejeitam concepções procedimentais. Como discípula confessa de Rawls, Anderson pode realmente ser tomada como um alvo central das críticas de Honneth ao liberalismo político. A fonte do desacordo seria a teoria do contrato social e remeteria à diferença entre os dois sentidos de reconhecimento e o que se compreende por "condições sociais da liberdade". Como Honneth tem uma interpretação "densa" e constitutiva do reconhecimento - ou seja, uma compreensão do reconhecimento como aquilo que possibilita a liberdade em primeiro lugar -, a visão procedimental de como ocorre a justiça é logicamente falha para ele. Ela pressupõe precisamente aquilo que pretende tornar possível. Apesar de rejeitar o paradigma da justiça distributiva, ao adotar a

2014, p. 254). Isso mostra que, inicialmente, a tradição socialista compartilhou com a tradição republicana o objetivo de "igualdade real". De fato, apesar das reservas de Marx, muitos socialistas defendem continuamente o objetivo da igualdade plena, sendo G. A. Cohen um dos recentes exemplos mais ilustres. Ironicamente, a descrição de Marx do primeiro estágio do socialismo em seu escrito Crítica ao programa de Gotha de 1875, parece muito próximo ao modelo descrito por Babeuf no "Manifesto dos Plebeus". 
teoria do contrato social, Anderson trata as "condições sociais" que possibilitam a liberdade como se elas fossem bens que os cidadãos com identidades estabelecidas podem demandar em relação aos outros. Da perspectiva de Honneth, a perspectiva de "segunda pessoa" que ela defende não é suficiente para evitar suas críticas, pois considera o reconhecimento entre as pessoas como algo externo à constituição de suas personalidades.

\section{c. Distribuição e igualdade real no modelo de "liberdade social" de Honneth}

Dadas essas diferenças, como Honneth discute a distribuição e como seria, para ele, a "igualdade real"?

A contraposição entre o modelo de "liberdade social" de Honneth e o modelo de "igualdade relacional" de Anderson já nos dá um elemento chave para responder tal questão. Honneth nunca esteve realmente interessado na igualdade em si. Ele aborda a igualdade como uma dimensão da autonomia que é, para ele, a norma mais fundamental (como afirma explicitamente em: 2014, p. 15). Justiça, nesse sentido, é o direito igual que cada indivíduo tem à autonomia plena, compreendida de forma "densa" como autorrealização. Isso não quer dizer que questões distributivas não sejam parte da justiça e sim que são resultados da ideia de que justiça significa garantir a cada indivíduo as condições sociais de sua autorrealização (Deranty, 2016).

Uma consequência importante da interpretação que Honneth faz das "condições sociais de liberdade" em termos de reconhecimento é a de que ela conduz a uma abordagem pluralista acerca das principais demandas normativas que os indivíduos podem fazer aos outros e ao coletivo. Afinal, a autorrealização individual engloba diferentes dimensões. Em "A textura da justiça" (2012b), por exemplo, Honneth menciona "necessidades, crenças e capacidades". Essas dimensões subjetivas se desenvolvem, por sua vez, em diferentes tipos de relação de reconhecimento. As "esferas de reconhecimento" em seu primeiro modelo, e as diferentes esferas institucionais em $O$ direito da liberdade (2014), correspondem precisamente aos tipos fundamentais de relações sociais, por meio dos quais os indivíduos realizam os diferentes aspectos de suas identidades, seu bem-estar e seus planos de vida. Isso significa que o reconhecimento é apenas um conceito genérico, que assume estruturas diferentes dependendo da esfera social em questão e do tipo de dimensão subjetiva que está em jogo nela. Como consequência dessa abordagem pluralista, a resposta de Honneth à questão da "igualdade real" seria a de que é impossível especificar um significado "verdadeiro" de igualdade, exceto no sentido genérico de direito igual às condições necessárias à autonomia plena. Igualdade quanto às condições de autonomia requer diferentes direitos e deveres entre amigos, amantes, familiares, bem como em relações anônimas entre consumidores e produtores que 
se encontram por meio de interações de mercado ou entre cidadãos que se engajam mutuamente na esfera pública. A partir dessa perspectiva pluralista, a equiparação de Anderson entre "relacional” e "democrático" parece precipitada e insuficientemente diferenciada.

De que maneiras Honneth se preocupa com a realização efetiva da "igualdade real"? Como no caso de Anderson, essa questão está diretamente vinculada à sua abordagem. Honneth tenta estabelecer um círculo virtuoso entre a definição de liberdade como liberdade social, o “ismo” político que, para ele, visava realizálo historicamente (o socialismo) e a abordagem da teoria política que se volta às "condições sociais da liberdade", tal como ele as compreende. Esse enfoque metodológico significa que a ontologia social realista deve fornecer os fundamentos da discussão sobre como as diferentes dimensões normativas da realização da verdadeira liberdade efetivamente se desdobrariam. "Realista" aqui significa que a ontologia social que fundamenta a teoria política tem que ser suficientemente detalhada, tem de fazer as distinções corretas entre as diferentes esferas sociais e seus respectivos mecanismos, permitindo que diferentes Eus formem diferentes Nós. A abordagem realista também tem de ser historicamente sensível, para que qualquer afirmação do teórico político a respeito do que as pessoas demandam umas às outras e à sociedade esteja ancorada nas sociedades modernas reais, para que seja possível mostrar que ela provém da história real dos movimentos sociais, por exemplo. Todos esses requisitos metodológicos explicam porque Honneth adota seu método original de "reconstrução normativa". O objetivo por trás desse método não é apenas prático, isto é, assegurar que as demandas normativas possuem suas raízes nas sociedades reais, mas também teórico.

Aconsequência desta circularidade metodológica entre a definição de liberdade (como "liberdade social”), o modo de construção da teoria (ontologia social realista e reconstrução normativa) e o movimento social privilegiado (socialismo) é a de que o último é mais do que apenas uma preferência subjetiva do teórico (Deranty, 2011). O mesmo tipo de circularidade evidenciado aqui está presente no trabalho de Anderson, neste caso em torno de uma compreensão "republicana" de liberdade e de igualdade como socialmente condicionadas.

É a partir destas perspectivas histórico-conceituais que farei, agora, algumas críticas aos dois pensadores. Eles resgatam duas tradições de pensamento político e de movimentos políticos reais para fundamentar as concepções de justiça que escolhem. Realizam tal resgate de maneira positiva, para mostrar que suas concepções de justiça têm efetivamente um ancoramento na sociedade moderna, e o fazem de maneira negativa, para demonstrar o caráter abstrato do paradigma da "justiça distributiva". Na tradição republicana e na socialista, a "igualdade real" era uma questão central para a justiça, tanto para os ativistas quanto para os pensadores: no 
que consiste a igualdade e como ela pode ser efetivamente realizada, em detrimento de concepções formais ou apenas realizações parciais dela. Considero esse método, que busca fundamentar a teoria política normativa em argumentos históricoconceituais, muito convincente. Há, todavia, um problema nesse caminho histórico. Há diferentes vertentes nas próprias tradições mobilizadas por Anderson e Honneth, vertentes que refletem criticamente sobre suas próprias proposições teóricas. Do ponto de vista da "igualdade real", enquanto uma demanda de agentes históricos e reais, as teorias deles talvez deixem de lado algumas considerações cruciais.

Para defender essa posição, farei referências à figura controversa de Babeuf, que foi jornalista, pensador político e agitador ativo no período da Revolução Francesa. Ele e seus companheiros, que prepararam a "Conspiração pela igualdade" em $1796^{4}$, escreveram uma série de textos programáticos e manifestos que correspondem à defesa mais radical, nos tempos modernos, da igualdade enquanto norma fundamental da vida social e política. Pode parecer arbitrário favorecer uma vertente específica dos primórdios do pensamento igualitário, dentre outras, para criticar os filósofos contemporâneos, por mais significativa que esta vertente tenha sido (para compreender a influência de Babeuf em Marx, ver por exemplo, Hobsbawm, 2012, p. 22-3). Duas razões justificam a relevância de Babeuf para um estudo crítico das vertentes de igualitarismo de Anderson e Honneth. A primeira é a de que Babeuf pode ser visto como um representante chave da tradição radical do republicanismo, que foi produzida diretamente pela Revolução Francesa e que, nos primeiros 50 anos do século XIX, até as revoluções de 1848, compartilhou muitas ideias e objetivos políticos reais com o movimento socialista emergente, tanto é que foi muitas vezes difícil separar as duas tradições em seus anos cruciais de formação. A segunda razão é a de que a própria Anderson estabelece Babeuf como um dos primeiros defensores do socialismo moderno e como um contraponto frente ao qual ela propõe sua versão americana do republicanismo radical e igualitário (2014b, 2016a).

\section{Igualdade relacional e liberdade social do ponto de vista da igualdade radical}

\section{a. Duas versões da igualdade republicana radical}

Assumirei aqi que os fatos básicos sobre Babeuf e sua "conspiração pela igualdade" são conhecidos pelo leitor (cf. Birchall, 2016). Anderson se volta a ele por diversas razões. Ela quer questionar uma concepção acerca da história da justiça redistributiva que identifica Babeuf como o primeiro autor desta tradição moderna (Fleischacker, 2004, p. 76-7), em favor de Thomas Paine. Este argumento histórico

4 Esse é o título da reconstrução de Philippe Buonarroti (1836) dos insurgentes reunidos em torno de Babeuf, que teve grande influência no pensamento socialista inicial, incluindo o de Marx. 
tem um significado conceitual e normativo. Para Babeuf, a propriedade privada é a raiz da desigualdade e, portanto, da injustiça. Disso, ele conclui que, para alcançar a justiça, a propriedade privada deve ser abolida e os recursos comuns produzidos pelos trabalhadores individuais devem ser redistribuídos de maneira inteiramente igualitária por um poder estatal centralizado. Do ponto de vista de Anderson, essa visão da justiça está errada por diversos motivos: ela justifica uma intervenção tirânica do estado nos assuntos privados das pessoas; leva a um nivelamento econômico que não pode ser justificado, por razões de eficiência e também porque aqueles que trabalham mais ou são mais talentosos não devem ser impedidos de ganhar mais. Em suas propostas de seguro social e de um fundo de renda, Paine, por outro lado, descreve um programa realista e equitativo para a "igualdade real", que garantiria apoio básico e igualdade universal de acesso a recursos materiais. Ele oferece uma proposta realista para combater as formas de dominação baseadas em privilégios, no poder do mercado e na transmissão deles por herança.

A apresentação feita por Anderson de Babeuf e seus companheiros não é generosa; é alheia às especificidades históricas e literárias dos textos que ela leu. Anderson seleciona passagens para construir a doutrina de Babeuf como uma antecipação direta da “ditadura totalitária” comunista. Todavia, a maioria dos pontos que ela apresenta como medidas programáticas são, de fato, descrições ideais que retratam como os Iguais esperavam que a sociedade seria no longo prazo, após a revolução igualitária. Para citar apenas um exemplo esclarecedor, quando Buonarrotti escreve: "Nada, em uma sociedade bem-ordenada, deve escapar do 'esprit du législateur'” (2015, p. 187), “esprit” não significa a “mente” inquisitiva do legislador, como lê Anderson, mas o espírito da constituição, em referência direta a Montesquieu e Rousseau.

Enquanto pragmatista, Anderson poderia ter sido sensível a outros aspectos dos escritos dos Iguais, sobretudo ao método por meio do pelo qual eles chegaram a suas afirmações. Em vez de usar o experimento de pensamento do contrato social como um procedimento de justificação, os planos para a igualdade social e política foram fundamentados em princípios básicos da lei natural - particularmente a velha ideia de que "a terra não pertence a ninguém"-, formulados e interpretados através de uma lente negativista, em oposição a situações de injustiça total. Nessa configuração metodológica, os princípios normativos e as medidas programáticas respondem diretamente a situações de negação flagrante do direito.

Anderson lê os textos dos lguais como se fossem escritos puramente programáticos, tal como o esquema de segurança social de Paine, mas eles são textos políticos que intervêm diretamente e são influenciados pelo contexto político. Esses textos misturam argumentos filosóficos (sofisticados) com referências à história imediata da Revolução, precisamente para cumprir com o que os autores viam como 
a promessa daquele momento decisivo na história moderna. É crucial ter isso em mente para aferir a força dos argumentos teóricos. Os textos podem exagerar em algumas de suas conclusões, mas foram formulados em uma situação de extrema tensão política, na qual posições opostas foram expressas e colocadas em prática com não menos radicalidade.

Os argumentos políticos estão vinculados à situação social e econômica, caracterizada por privações e humilhações terríveis para a grande maioria. Esse vínculo entre descrição e princípios normativos se aplica, em particular, a mais significativa edição de Babeuf em Le Tribun du Peuple (número 35, de 30 de novembro de 1795; Babeuf, 2009 [1795], p. 321-336), que apresenta o famoso "Manifesto dos Plebeus" (Birchall, 2016, p. 195-9). Anderson não atenta às passagens que precedem as páginas nas quais o "Manifesto dos Iguais" é resumido5. Páginas que parecem totalmente desatualizadas hoje, por conta de seu pathos grandiloquente e dos floreios do século XVIII. Nos esforçamos para nos relacionar a elas de maneira significativa. O leitor acadêmico é tentado a pular diretamente para as páginas que se assemelham mais a argumentos da teoria política, mas pular essas páginas seria um erro. As passagens descrevendo o sofrimento da população proletária funcionam como uma camada argumentativa fundamental para os argumentos políticos. Este é o primeiro modo de utilização de um método negativista: a situação factual de extrema miséria mostra que o sistema existente é inválido com base em seus próprios princípios, sobretudo, o da natureza sagrada da propriedade privada, que impede a maioria despossuída de ter acesso aos bens que uma minoria tem em excesso.

O simples fato da enorme desigualdade é, em si e por ele mesmo, uma injustiça, tanto em sentido relativo quanto em sentido quantitativo, na medida em que não parece justificável que alguns possam ter tanto ao mesmo tempo em que a maioria tem tão pouco que não consegue nem sobreviver. Esse tipo de injustiça é traduzido por Babeuf em um princípio normativo geral: “ninguém pode justificadamente dizer que qualquer outro de seus semelhantes seja menos feliz do que ele" (Babeuf, 2009 [1795], p. 326). Babeuf tem um conceito mínimo de "felicidade" em mente: quaisquer recursos necessários em um determinado momento para que um indivíduo tenha suas necessidades sociais básicas atendidas. Em um fragmento de um decreto econômico escrito na mesma época, temos uma noção concreta do que os Iguais compreendiam por felicidade nesse sentido mínimo: “acomodações saudáveis, confortáveis e com mobiliário decente; roupas para trabalho e lazer; lavanderia, iluminação e aquecimento; uma quantidade suficiente de comida; assistência médica" (Birchall, 2016, p. 202). O princípio de que "ninguém pode justificadamente dizer que qualquer outro de seus semelhantes seja menos

50 "Manifesto dos Iguais" foi o texto escrito por Sylvain Maréchal em 1796, clamando o povo a se levantar em nome da "igualdade ou morte" (Birchall, 2016, p. 192-5). 
feliz do que ele" poderia ser lido como um argumento da teoria do contrato social. De fato, Babeuf o formulou fazendo referência a Rousseau. Mas deve-se prestar atenção às palavras exatas. Um argumento do contrato social enfatizaria a primeira pessoa: as pessoas não concordariam racionalmente em colocar a si mesmas em uma posição na qual estariam em desvantagem em comparação aos outros. Babeuf, entretanto, não se refere à racionalidade autointeressada, mas à justificação moral: para mim, é impossível justificar uma ordem na qual eu sei que estaria em vantagem sobre outros. Esta é uma outra forma do método negativista, um segundo argumento sobre a injustiça. Trata-se, de modo claro, de um argumento que adquire uma força específica em uma situação na qual os ricos e os poderosos estão, precisamente, em uma situação de extrema vantagem, na qual desfrutam de imensa riqueza enquanto a maioria passa fome e vê seus filhos morrerem.

Tudo isso nos alerta para a necessidade de parar e refletir sobre a força normativa dos escritos de Babeuf e sobre o que eles podem nos ensinar hoje novamente, em um período no qual a desigualdade está crescendo e a diferença entre ricos e pobres - algo notável no país de Anderson, por exemplo - assume novamente grandes proporções. Em vez de procurar, de forma anacrônica, por premissas ditatoriais em Babeuf, podemos encontrar inspiração em como ele vincula a descrição da situação de injustiça substancial com princípios políticos normativos ${ }^{6}$. A demanda por igualdade pode ser justificada, em princípio, por leis naturais e argumentos de contrato social, mas surge, antes de tudo, como uma consequência necessária da abolição da injustiça: se a desigualdade radical é flagrantemente injusta, então a justiça requer a supressão da desigualdade, ou pelo menos sua redução significativa. É isso o que a "igualdade real" quer dizer em primeiro lugar. Sua urgência decorre, antes de mais nada, do fato de que o que está dado é o seu oposto absoluto.

É claro que, a princípio, a inferência radical de Babeuf não parece se sustentar: o fato de que uma grande desigualdade é injusta significa apenas que ela deveria ser reduzida, e não que uma igualdade perfeita deva ser estabelecida. Rousseau exigiu apenas que "todos tivessem algo e que ninguém tivesse muito", passagem que Babeuf cita frequentemente. Anderson também exige uma redução drástica da desigualdade econômica, uma vez que transforma a igualdade real, social e política em uma ficção.

O método negativista, porém, está na base de outro conjunto de considerações que explicam porque Babeuf e seus companheiros não exigiam apenas mais igualdade, mas uma implementação radical da igualdade. Para eles, "igualdade real" significava igualdade perfeita. É esse conjunto de considerações que de fato distingue a abordagem de Babeuf da de Anderson e, como veremos na próxima seção,

6Cf. Deranty (2016), texto no qual eu tentei expor que Marx usa uma estratégia similar no livro primeiro d'O capital. 
da de Honneth. Mesmo que não desejemos seguir completamente Babeuf e os seus companheiros em seus planos radicais, lições substanciais podem serem aprendidas a partir de seus argumentos e de como responderam intelectualmente a uma situação de extrema emergência.

O principal uso teórico que Babeuf e os Iguais fazem da referência à desigualdade injusta é identificar suas causas sociais e argumentar contra elas. 0 argumento negativo, portanto, não é apenas contra a desigualdade, mas contra as causas dessa desigualdade. É, sob essa luz, que a propriedade privada é debatida. Babeuf não deduz a falta de validade normativa da propriedade privada apenas dos princípios positivos da lei natural, mas em combinação com um argumento negativo, baseado na realidade e na história da injustiça. Para a tradição rousseauista, o principal problema da propriedade privada é que ela é a raiz das desigualdades, que se acumulam ao longo do tempo e se cristalizam em estruturas de dominação social, produzindo grandes diferenças de poder social, o que acaba gerando aquele tipo de injustiça extrema que Babeuf relata enquanto jornalista. Outras fontes de desigualdade social que contribuem para reforçar os efeitos da propriedade privada sobre a desigualdade são identificadas: a transmissão da propriedade por herança; o fato de que alguns podem adquirir direitos de propriedade sobre outras pessoas por meio de contratos de trabalho; o de que possuir atributos pessoais, morais ou intelectuais que são socialmente favorecidos gera maiores benefícios sociais para alguns; o de que a educação reforça hierarquias sociais e culturais, particularmente aquelas relacionadas à divisão entre trabalho intelectual e manual, inculcando as representações subjacentes a essas hierarquias às gerações mais jovens e selecionando ativamente os indivíduos de modo a reproduzir as distinções entre a elite e a plebe (Babeuf, 2009 [1795], p. 330-333). O fenômeno da injustiça como um todo resulta, portanto, de uma complexa combinação de mecanismos sociais centrados em torno da propriedade. 0 que poderíamos chamar de riqueza "privatizada" (de terras, de pessoas e até de atributos pessoais) cria situações de desigualdade social que, no longo prazo, sempre podem ser traduzidas, e na história frequentemente o são, em total destituição para a maioria. Desse ponto de vista, mesmo que em um momento específico a desigualdade seja temporariamente controlada, nas sociedades organizadas em torno da privatização da riqueza continua sempre existindo um potencial para aumento significativo da desigualdade, que leva à penúria de muitos ou, pelo menos, a diferenças significativas e injustificáveis nos graus de "felicidade", tal como definida anteriormente.

Do ponto de vista do princípio positivo recusado acima, as diferenças significativas na "felicidade" são intrinsecamente errôneas e as formas graves de privação são uma injustiça absoluta, dado que negam o direito de indivíduos de viverem bem e, em circunstâncias extremas, até mesmo de sobreviverem. Esses 
erros, porém, também resultam da violação de um princípio positivo e normativo, a saber, o de que a riqueza geral deve ser compartilhada por todos, uma vez que foi produzida por todos, e o de que a propriedade privada, deste ponto de vista, é uma riqueza social que foi indevidamente privatizada. Essa privatização da riqueza social ocorre precisamente por meio dos mecanismos de desigualdade social, cujas origens principais foram identificadas acima (herança, alienação, meritocracia). 0 resultado de todos esses elementos (privatização injustificada que induz dominação, e desigualdade que produz privação) não é apenas o simples fato de que alguns têm muito e outros muito pouco, mas o fato de que "alguns conseguem ter muito apenas fazendo com que outros tenham muito pouco". O cerne é a dinâmica social da dominação, cujo objetivo é fazer com que os outros tenham muito pouco para que se possa ter muito.

Essa visão da injustiça não é mais compatível com a concepção de Anderson, de acordo com a qual alguma desigualdade é defensável, sob as condições que vimos acima. Para Babeuf, é normativamente impossível justificar a desigualdade, pois a desigualdade levará, em algum momento, à distribuição injusta. Ela significa que inevitavelmente alguns terão muito pouco, como uma questão de fato e como a história mostra, porque é uma lei social que, se alguns têm muito, é porque fizeram outros terem muito pouco. Assim que a desigualdade é justificada, a injustiça é justificada enquanto uma potencialidade aceitável da organização social.

Isso explica a insistência na igualdade plena, sem exceção, até mesmo para aqueles que são mais produtivos ou merecedores. Nos termos da lei natural, parece equitativo que, se todos têm direito igual à riqueza social, então todos deveriam ter a mesma quantidade, em relação ao que precisam para sua própria "felicidade". Aqui devemos notar a sofisticação do argumento de Babeuf em um artigo de jornal escrito em um período de grave emergência política. Ele responde de modo direito e antecipado a uma objeção levantada por igualitaristas da fortuna: e se a minha felicidade requer que eu receba mais e bens mais valiosos, de modo que o princípio da igualdade para a "felicidade" leve à desigualdade material em meu favor? Babeuf responde lançando mão da concepção minimalista de felicidade já mencionada, caracterizando-a em termos negativos como "suficiência" ou impedimento da miséria. Em uma situação de escassez, não há uma terceira opção entre suficiência para todos com base na redistribuição igualitária e distribuição desigual que leva a maioria à privação. Acrescentar a condição de escassez ao argumento "baseado na suficiência" força uma conclusão radicalmente igualitária, ou ao menos substantivamente igualitária, visto que apenas uma condição de opulência social indefinida poderia permitir que o suficiente para todos possa ser traduzido em partes desiguais. Essa é uma réplica direta para a posição contra a igualdade material substantiva, que tem no trabalho de Harry Frankfurt sua defesa mais conhecida (1987). Mas o argumento mais 
básico, proveniente de Rousseau e da história social, é o negativo: assim que você justifica as desigualdades com base no direito de privatizar a riqueza, você permite a revelação da lógica social que leva à desigualdade injusta. A história mostra como essa desigualdade muitas vezes termina produzindo uma injustiça absoluta ou, ao menos, desigualdades significativas e injustificáveis em relação à "felicidade".

0 argumento negativo é significativo para discussões contemporâneas por sinalizar a necessidade de aumentar nossa sensibilidade para qualquer desigualdade, uma vez que ela é um possível sinal de que a organização social está no caminho para injustiças significativas ou, mesmo, extremas. Ele também é significativo pois enfatiza as várias dimensões da desigualdade que têm efeitos diretos sobre a justiça social. Se a preocupação central é com os mecanismos pelos quais a desigualdade se torna uma força social, levando a situações de injustiça, então temos que olhar para a desigualdade material assim como para outras formas de desigualdade, como importantes fatores de injustiça. A desigualdade nas representações sociais, sobretudo aquelas relacionadas à hierarquia das profissões, torna-se problemática do ponto de vista da justiça social. Babeuf argumenta explicitamente que é errado basear a desigualdade social e econômica em representações arbitrárias sobre os valores relativos de contribuições sociais.

Do ponto de vista deste vínculo entre desigualdade e injustiça via dominação social, o modelo de Anderson não resolve a questão. Como uma republicana, ela também está preocupada com os mecanismos de dominação social (ver a taxonomia das formas de dominação em 2010b, p. 1-22), mas ela não leva suficientemente em consideração que a propriedade desigual é um dos mecanismos que mais geram e reforçam posições de privilégio e situações de dominação. Anderson também entra em discussões com os igualitaristas da fortuna sobre a justificabilidade da igualdade de recursos, por um lado; por outro, sua abordagem relacional a leva a enfatizar exclusivamente modalidades de interação social, de modo que ela não parece considerar os vínculos históricos e sociológicos entre a propriedade privada e a dominação. Ela não tematiza isso como um problema que a teoria política tem de abordar especificamente. No contexto da enorme concentração de poder nas elites e do enfraquecimento da democracia política como um resultado da desigualdade social, os aspectos perturbadores de uma grande desigualdade social deveriam ser uma preocupação central para ela. Uma leitura mais generosa de Babeuf a teria alertado para uma preocupação que ele herdou da mesma tradição do republicanismo radical que pretende recuperar, a de que a democracia é incompatível com uma grande desigualdade econômica. Uma postura "republicana radical" deveria estar cansada de oferecer justificativas para qualquer desigualdade, e deveria estar particularmente preocupada em identificar as barreiras sociais e políticas que podem interromper os mecanismos que levam a estruturas rígidas de dominação. 
Além disso, por ser uma seguidora de Rawls e entrar no quadro das discussões sobre "justiça distributiva”, Anderson adota uma concepção não-problemática de talento, como se houvesse uma hierarquia objetiva de tarefas em termos de complexidade e valor social, e apenas aqueles com qualidades pessoais superiores ou motivação conseguissem desempenhá-las. A noção de que “talentos” são construções sociais, de que algumas atividades sociais e profissionais poderiam ser privilegiadas de maneiras arbitrárias, não é levada suficientemente em consideração por ela. $\mathrm{Na}$ verdade, como argumenta Babeuf, é possível mostrar que parte do mérito individual relacionado a contribuições particulares possui condições sociais. Contribuições individuais mobilizam recursos materiais e simbólicos que o indivíduo não produziu, mas dos quais depende para realizar sua própria atividade (Birchall, 2016, p. 196). Além disso, nos casos em que determinados desempenhos individuais parecem particularmente valiosos e, portanto, o indivíduo responsável por eles é merecedor de estima social, se ele se beneficiou de uma educação privilegiada, é altamente provável que outros poderiam executar a atividade tão bem quanto ele caso tivessem a oportunidade: uma "distribuição igual de conhecimento entre todos tornaria os indivíduos aproximadamente iguais em capacidade e até mesmo em talento". Essa não é uma consideração de arbitrariedade moral ou sorte, como no paradigma da justiça distributiva, mas uma afirmação substantiva sobre as qualidades inatas da inteligência. Babeuf defende uma teoria similar àquela proposta pelo companheiro republicano revolucionário, Joseph Jacotot, cujo esquecido nome Jacques Rancière reviveu em $O$ mestre ignorante. Mas se todas as inteligências são iguais em princípio e somente as circunstâncias permitem que alguns as desenvolvam plenamente ou as tornem frutíferas, isso reduz significativamente o valor do mérito individual e do "talento". Tais teorias igualitárias sobre a inteligência e a educação estão distantes da monstruosa "nivelação" que Anderson vê nelas. Asseverar a igualdade de inteligência e o valor comparável das contribuições sociais não leva à desconsideração dos indivíduos aparentemente mais merecedores, apenas exige que todos tenham acesso ao conhecimento e à mesma qualidade de educação de que indivíduos privilegiados desfrutaram. Anderson defende a igualdade de oportunidade e o igual acesso à educação, mas não porque isso equalizaria os talentos, e sim porque alguns merecedores, que eram até então indivíduos desprivilegiados, teriam agora acesso a ocupações e papéis sociais que são objetivamente superiores.

Poderíamos nos perguntar como esses pressupostos meritocráticos podem ser compatíveis com um ethos igualitário. A tradição republicana insiste no fato de que a democracia é mais do que uma estrutura institucional, que ela deveria ser um ideal para a vida social como um todo. Anderson concorda inteiramente com isso, que é precisamente o que está por trás de sua ênfase na igualdade como uma relação. Como um tal ideal se compatibiliza com a suposição não problemática de que alguns 
são intrinsecamente superiores e algumas contribuições sociais são obviamente mais valiosas que outras?

Surpreendentemente, a afirmação republicana radical de Babeuf sobre a igualdade de inteligência fornece o elemento final de seu comunismo: toda riqueza é socialmente produzida; todas e todos contribuem para a riqueza social; é pouco o que distingue uma contribuição das demais; mesmo se houver diferenças na contribuição, há igualdade na necessidade; por conseguinte, todas e todos deveriam receber quantidades iguais da riqueza produzida universalmente de forma proporcional ao que eles precisam para atingir suficiência em suas circunstâncias. Longe de ser uma distopia ditatorial, o comunismo de Babeuf pode ser lido como uma aplicação consistente dos princípios republicanos radicais. Ele antecipa, em suas características centrais, o modelo de "justiça contributiva" proposto por Paul Gomberg (2007).

\section{b. 0 socialismo de Honneth do ponto de vista da igualdade radical}

O que os desafios de Babeuf implicam para o tipo de socialismo de Honneth?

Primeiro, a maneira inicial com que Honneth apresenta sua teoria do reconhecimento é receptiva à abordagem negativa delineada acima. É verdade que, em Luta por reconhecimento, a lógica geral do reconhecimento e dos diferentes tipos de demandas por reconhecimento foram estabelecidas através de argumentos positivos, mas o fundamento para estas descrições positivas, aquilo que lhes fornecia orientação heurística crucial, era, por um lado, a fenomenologia das reações negativas de indivíduos e grupos expostos a experiências de sofrimento social e injustiça e, por outro, a história e a sociologia das lutas sociais contra a injustiça. 0 modelo mais recente, apresentado em $O$ direito da liberdade, ao contrário, está ancorado nas instituições da sociedade moderna que realizam e reforçam as diferentes esferas da "liberdade social", tendo perdido contato com essa fundamentação negativa. Honneth, em diversos textos recentes, prestou atenção ao preceito metodológico de Habermas, que condena a falácia genética que consiste em extrair afirmações normativas de fatos sobre a vida individual e social.

A mesma ruptura pode ser sublinhada no que diz respeito aos vínculos entre desigualdade social e justiça democrática. Por conta de sua forte fundamentação sociológica, o modelo inicial do reconhecimento abriu espaço para uma teoria da dominação social. De fato, a ideia mesma de uma luta por reconhecimento enfatiza os obstáculos sociais à inclusão plena e à igualdade na autorrealização. Em seus primeiros textos, Honneth (2007) se concentrou especificamente nos obstáculos à inclusão social plena, incluindo os obstáculos baseados na desigualdade material. Isto tornou o primeiro modelo político de Honneth receptivo às preocupações de Babeuf sobre a desigualdade, não apenas como um sinal, mas também como um vetor de 
injustiça. Apesar dos pressupostos meritocráticos de Honneth acerca do valor das contribuiçõos sociais na terceira esfera de reconhecimento, ele aplicou a "luta por reconhecimento" diretamente aos pressupostos culturais que sustentam juízos de valor sobre essas contribuições. Isto abriu a porta para uma desconstrução igualitária da hierarquia de profissões e de atividades sociais, em particular no que se refere à divisão entre trabalho intelectual e manual ou, inclusive, entre trabalho pago e não pago (1995, p. 129-130). Deste ponto de vista, o primeiro ideal de "autorrealização" universal de Honneth poderia ser compatível com o lema republicano radical segundo o qual "o objetivo da sociedade é a felicidade comum".

No novo modelo de reconhecimento e no trabalho sobre socialismo que dá continuidade a ele, não há mais qualquer interesse em desenvolver uma teoria explicita sobre dominação social. A ênfase está em identificar o ideal moderno de liberdade como liberdade social e como diferentes esferas da sociedade moderna realizaram gradualmente este ideal e forneceram conteúdos específicos a ele. Esta reconstrução histórica e normativa engloba a dimensão das lutas sociais, na medida em que estas indicam as diferentes maneiras pelas quais os indivíduos modernos procuraram ampliar e realizar aspectos de suas liberdades individuais (Honneth, 2014, p. 208). Por sua vez, essas referências às lutas sociais indicam, de modo negativo, as forças antagônicas que correspondiam aos obstáculos à liberdade e, com isso, impediam a igualdade social. Porém, essas lutas por igualdade e as forças sociais que sustentam os diferentes tipos de privilégios só importam na medida em que revelam algo sobre o conteúdo dos diferentes aspectos da liberdade social. Elas não são mais o foco do esforço teórico. Se ampliações da liberdade social ocorreram sem luta, por exemplo, através da mera força do progresso moral, isso é indiferente para o novo modelo crítico. Isto, do ponto de vista da abordagem negativista usada por Babeuf, significa que os vínculos entre as formas de desigualdade social e a injustiça saíram do horizonte.

Ainda mais preocupante, de uma perspectiva igualitária radical: a ênfase na "moralidade do mercado", na ideia de que as interações mercadológicas estão ancoradas em expectativas morais, que fazem do próprio mercado uma esfera de liberdade social, significa que o vínculo entre desigualdade econômica e déficit democrático, estabelecido pelos lguais, corre o risco de ser afrouxado. Honneth discordaria disso, visto que afirma precisamente que estas expectativas morais, com as quais indivíduos modernos entram nas interações econômicas mediadas pelo mercado, restringem este último. No mercado de trabalho, por exemplo, o progresso histórico, impulsionado pelo movimento trabalhista, garantiu que princípios como o do salário equitativo, o direito a uma ocupação significativa ou o direito a opinar sobre a organização econômica fossem gradualmente estabelecidos (2014, p. 223251). Entretanto, em sua tentativa de dar espaço para mecanismos mercadológicos 
como um elemento central de uma versão modernizada de socialismo, o modelo político de Honneth se aproxima do modelo republicano de Anderson. Assim como ela, Honneth se recusaria a ver a propriedade privada como incompatível com a liberdade social. Ele afirma isto explicitamente tendo em vista o que a propriedade privada permite que o indivíduo faça em relação aos demais, a saber, ela oferece uma esfera isolada que o separa dos demais e, com isso, o permite revisar seus próprios planos de vida (2014, p. 73-82). Mas não é isso o que está em questão aqui. Babeuf também poderia aceitar esse sentido de "privado" como parte do que a "suficiência" requer. 0 que está em questão aqui, ao contrário, é a propriedade da riqueza socialmente produzida, tanto em termos normativos positivos, do ponto de vista da distribuição compartilhada de "felicidade", quanto do ponto de vista da injustiça.

A preocupação igualitária de Babeuf com a propriedade não é necessariamente tão ingênua ou desavisada como os dois pensadores poderiam acreditar. Babeuf enfatiza a propriedade privada porque a posse de terras em seu tempo era a principal fonte de criação de riqueza. Como já foi sugerido, contudo, enxergar sua preocupação com a privatização de terras como uma preocupação com a privatização de riqueza socialmente produzida está de acordo com o espírito de sua proposta. Acontece que, hoje, muitos pensadores políticos contemporâneos procuram desenvolver modelos econômicos alternativos que desafiam a ideia de que uma economia moderna está necessariamente baseada na propriedade privada dos meios de produção. Por exemplo, com relação à teoria da firma, Isabelle Ferreras (2017) mostra a falácia que consiste em reduzir a firma, uma instituição que envolve múltiplos grupos com racionalidades divergentes, à corporação, cujo único interesse é a maximização do retorno de investimentos aos acionistas. $\hat{E}$ um fato historicamente contingente que a posse de ações da corporação tenha se traduzido em direitos de propriedade sobre toda a firma, os quais superam quaisquer outros direitos ou interesses, colocando os trabalhadores sob o comando quase absoluto dos acionistas e seus representantes na firma e sacrificando quaisquer outros interesses ou metas que poderiam ser perseguidos pela firma em nome da recompensa financeira para os investidores. Sobre as questões de eficiência, não é necessariamente o caso que as interações de mercado dependam da propriedade privada dos meios de produção. Pode haver outros meios de integrar os diferentes agentes envolvidos na produção (trabalhadores, gerentes, clientes e comunidades) do que por meio de relações de obediência unilateral asseguradas por direitos intocáveis à propriedade (Borrits, 2018). De uma perspectiva crítica mais básica, Honneth, assim como Anderson, não considera impossível o vínculo delineado por Babeuf entre a acumulação de propriedade privada e a existência de estruturas de classe, o que impossibilita a igualdade social e, com ela, a igualdade de autorrealização pretendida por ele. 


\section{Referências}

Anderson, E. (1999). What is the point of Equality? Ethics, 109, 287-337. [Qual é o sentido da igualdade? Revista Brasileira de Ciência Política, 15, 163-227]. DOI: https: //doi.org/10.1590/0103-335220141507

Anderson, E. (2008). How should egalitarians cope with market risks? Theoretical Inquiries in Law, 9(1), 239-270.

Anderson, E. (2010a). The Imperative of Integration. Princeton: Princeton University Press.

Anderson, E. (2010b). The Fundamental Disagreement between Luck Egalitarians and Relational Egalitarians. Canadian Journal of Philosophy, 36, 1-23. DOI: https: / / doi.org/10.1080/00455091.2010.10717652

Anderson, E. (2014a). The Quest for Free Labor: Pragmatism and Experiments in Emancipation. The Amherst Lecture in Philosophy 9, 1-44.

Anderson, E. (2014b). A World turned upside down. Social Hierarchies and a New History of Egalitarianism. Juncture 20(4), 58-267. DOI: https://doi.org/10.1111/j.2050-5876.2014.00763.x

Anderson, E. (2015a). Equality and Freedom in the Workplace. Recovering Republican Insights. Social Philosophy and Policy, 31(2), 48-69. DOI: https: / / doi.org/10.1017/S0265052514000259

Anderson, E. (2015b). Moral Bias and Corrective Practices: A Pragmatist Perspective. Proceedings and Addresses of the APA, 89.

Anderson, E. (2016a). Thomas Paine's “Agrarian Justice” and the Origins of Social Insurance. Ten Neglected Classics of Philosophy, pp.55-83. Oxford: Oxford Univeristy Press.

Anderson, E. (2016b). Common Property. How Social Insurance Became Confused with Socialism. Boston Review, July 25.

Anderson, E. (2017). Private Government. How Employers rule our Lives (and why we don't talk about it). Princeton: Princeton University Press.

Babeuf, G. (2009 [1795]). Manifeste des Plébéiens. In: Mazauric, C. (ed.). Babeuf. Écrits, pp.321-336. Paris: Le Temps des Cerises.

Birchall, I. (2016). The Spectre of Babeuf. Chicago: Haymarket Books.

Buonarroti, P. (1836). History of Babeuf's Conspiracy for Equality. London: H. Hetherington.

Buonarroti, P. (2015). Conspiration pour l'Égalité dite de Babeuf. Paris: La fabrique.

Borrits, B. (2018). Au-delà de la Propriété. Paris: La Découverte.

Cohen, G.A. (1989). On the Currency of Egalitarian Justice. Ethics 99(4), 906-944. DOI: https: //doi.org/10.1086/293126

Cohen, G.A. (2009). Why Not Socialism? Princeton: Princeton University Press.

Deranty, J.-P. (2011). "Reflective Critical Theory: a Systematic Reconstruction of Axel Honneth's Social Philosophy”. In: Petherbridge, D. (ed.). Axel Honneth. Critical Essays, p.58-88. Leiden: Brill.

Deranty, J.-P. (2016). "Between Honneth and Rancière: Problems and Potentials of Contemporary Critical Theory". In: Genel, K. and Deranty, J.-P. (eds). Recognition versus Disagreement: A Critical Encounter on the Politics of Freedom, Equality and Identity, pp.55-65. New York: Columbia University Press. 
Ferreras, I. (2017). Firms as Political Entities. Democracy through Economic Bicameralism. Cambridge: Cambridge University Press.

Fleischacker, S. (2004). A Short History of Distributive Justice. London: Harvard UP.

Frankfurt, H. (1987). Equality as Moral Ideal. Ethics 98(1), 21-43. DOI: https: / / doi.org/10.1086/292913

Gomberg, P. (2007). How to make Opportunity equal. Race and Contributive Justice. London: Blackwell.

Hayat, S. (2018). "Working class socialism in France in 1848". In: Moggach, D. and Stedman-Jones, G. (eds.). The 1848 Revolutions and European Political Thought, pp.120-139. Cambridge: Cambridge University Press.

Hobsbawn, E. (2012). How to change the world: Reflections on Marx and Marxism. Yale University Press.

Honneth, A. (1995). The Struggle for Recognition. The Moral Grammar of Social Conflicts. Cambridge: Polity. [Honneth, A. (2003). Luta por reconhecimento: a gramática moral dos conflitos sociais. Tradução de Luiz Sérgio Repa. São Paulo: Editora 34.]

Honneth, A. (2007). "Moral Consciousness and Class Domination. Some Problems in the Analysis of Hidden Morality". In: Honneth, A. Disrespect. The Normative Foundations of Critical Theory, pp.8-96. London: Wiley.

Honneth, A. (2012a). “Labour and Recognition. A Redefinition”. In: Honneth, A. The I in We, pp.56-75. Cambridge: Polity.

Honneth, A. (2012b). "The Fabric of Justice. On the Limits of Contemporary Proceduralism". In: Honneth, A. The I in We. Studies in the Theory of Recognition, pp.35-55. London: Wiley. [Honneth, A. (2009). A textura da justiça: sobre os limites do procedimentalismo contemporâneo. Civitas - Revista De Ciências Sociais, 9(3), 345-368. DOI: https://doi.org/10.15448/1984-7289.2009.3.6896

Honneth, A. (2014). Freedom's Right. The Social Foundations of Democratic Life. Cambridge: Polity. [Honneth, A. (2015). O Direito da liberdade. Tradução de Saulo Krieger. São Paulo: Martins Fontes.]

Honneth, A. (2017). The Idea of Socialism. Towards a Renewal. Cambridge: Polity.

Rancière, J. (1987). Le Maître ignorant. Paris: Fayard. [Rancière, J. (2007). O mestre ignorante. Tradução de Lílian do Valle. Belo Horizonte: Autêntica.]

Rosanvallon, P. (2013). The Society of Equals. London: Harvard University Press.

Wood, A. (2014). "Marx on Equality". In: Wood, A. The Free Development of Each: Studies on Freedom, Right, and Ethics in Classical German Philosophy, pp.252272. Oxford: Oxford University Press. 